AN EPIDEMIOLOGICAL STUDY TO ASSESS THE PREVALENCE OF PKDL IN PEDIATRIC AGE GROUP IN ENDEMIC AREAS OF BIHAR

doi:10.1136/archdischild-2012-302724.0847

V Ravidas. Indian Council of Medical Research, RMRIMS, Patna, India

Post Kala-azar Dermal Leishmaniasis (PKDL) is a dermatosis usually occurs as a sequel of Visceral Leishmaniasis (VL), commonly known as kala-azar (KA), caused by L. donovani (L.d.) and characterized by macular, maculo-papular and nodular skin lesion on the whole body surface. It is of considerable epidemiological importance particularly in India because it acts as reservoir for transmission of parasite through sandflies. In India, it appears after a long period, usually 1-2 years or more, in 5-10\% of VL cases, but it may also occur without manifestation of VL.

Emphasis on PKDL reporting, the prevalence of PKDL cases is not much clear. Objective to assess prevalence of PKDL in Children in endemic community of Bihar, survey was carried out in a Rukhai village of Chandi PHC, regular occurrences of VL cases and PKDL have been reported. Out of 223 individuals (52\% male, 48\% female), 41 had past history of VL occurred during 2001 to 2007, 40 cases were treated with recommended dosage of Sodium Antimony Gluconate and only one case Miltefosine; and all were cured. A total of 11 individuals (male-5, female-6) were identified as PKDL cases. Out of 23,915 populations from 4323 households, 12 PKDL cases (Male 5, Female 7) were detected. Out of 12, 9 had past history of VL.

Less than 1 VL case per 10,000 population at sub-district level under KA elimination programme, the estimated prevalence of $\mathrm{PKDL}$, is a matter of concern for policy planners.

\section{CLINICAL, BIOCHEMICAL AND ETIOLOGICAL PROFILE OF FULMINANT HEPATIC FAILURE OF VIRAL ETIOLOGY IN CHILDREN}

doi:10.1136/archdischild-2012-302724.0848

D Bhat, G Dhooria, B Jain, B Dhillon. Dayanand Medical College, Ludhiana, India

Viral Hepatitis is a major health problem endemic in many parts of the world. Fulminant hepatic failure is a rare condition that occurs in only $1 \%$ of patients hospitalised with an acute viral hepatitis. There is a paucity of literature describing spectrum of fulminant hepatic falure in children in India.

Objective To study the clinical, biochemical and etiological profile of fulminant hepatic failure (FHF) of viral etiology in children.

Methods The study was conducted in 30 children aged group between 1-15 years admitted with FHF of proven viral etiology in Dayanand Medical College and Hospital, Ludhiana. A detailed clinical evaluation including history, physical signs, staging of hepatic encephalopathy with relevant investigations and viral markers were entered in a pretested proforma.

Results Twenty nine patients $(96.7 \%)$ had enterically transmitted hepatitis. Viral markers for HAV alone was positive in 20 patients $(66.67 \%)$ and in combination were positive in 28 patients (93.3\%), HEV in 7 patients (23.3\%) and HBV in 5 patients $(16.7 \%)$. Eight patients had mixed viral infections. The clinical features included fever and jaundice(100\%), anorexia (83.3\%), vomiting $(76.7 \%)$, nausea $(73.3 \%)$. Complications seen were cerebral edema $(53.3 \%)$, decreased urine output (30\%), GI bleeding $(16.6 \%)$ and septicaemia (16.6\%). The overall survival rate of FHF was seen to be $73.3 \%$.

Conclusions HAV was found to be the commonest viral infection causing FHF either alone or in combination with others. Importance of vaccination of children with HepatitisA and HepatitisB vaccine and improvement in sanitation in prevention of FHF cannot be overemphasised.

\section{9 COMPLICATED URINARY TRACT INFECTION IN NEONATES}

doi:10.1136/archdischild-2012-302724.0849

'L Spahiu, $2 \mathrm{~V}$ Hasbahta, ${ }^{2} \mathrm{G}$ Ceku, ${ }^{3} \mathrm{M}$ Marniku. ${ }^{1}$ Pediatric, University Clinical Centre of Kosova, Pediatric Clinic; ${ }^{2}$ Pediatric; ${ }^{3}$ Radiology, University Clinical Centre of Kosova, Prishtina, Kosovo

Obstructive uropathies present changes in anatomy and function of urinary tract. They are usually discovered during the examination of urinary tract infection.

Aim of study To present the most frequent causes in the most frequent types of obstructive uropathyes in neonates.

Materials and Methods In our study, 38 neonates were included and they were diagnosed in the Pediatric Clinic during the period of time 2010/2011. They were diagnosed by bacteriological examination of urine, renal ultrasonography, and radiologic examination such as voiding cystourethrogram and excretory urogram.

Results of study From 38 neonates, $52.24 \%$ were males and $47.76 \%$ were females. Vesicoureteral refluks (VUR) is the most common obstructive uropathy in this age and is present in $75 \%$ of all cases. Megaureter is present in $25 \%$ of cases and posterior urethral valves are present in $12.5 \%$ of cases. Results of bacteriological examination show that VUR is connected with Klebsiella pneumonie in $65.1 \%$ of cases, while with Ecoli in $34 \%$ of the cases. At megaureter the most frequent cause of infection was Klebsiella pneumonie in $68.1 \%$, while E.coli in $38.2 \%$ of cases. At posterior urethral valves, E coli was the most frequent cause of infection in $56.3 \%$ of the cases. Klebsiella pn. was present in $16.7 \%$ of the cases and Proteus spp. was isolated in $25 \%$ of cases. Conclusion According to the results of the study, it can be concluded that the most frequent cause of urinary tract infection at obstructive uropathies is Klebsiella pneumonie.

\section{URINARY TRACT INFECTIONS IN CHILDREN IN JORDAN: THE MICROBIAL PATTERN AND RESISTANCE TO ANTIBIOTICS}

doi:10.1136/archdischild-2012-302724.0850

AA Almatti. Pediatrics, Islamic Hospital, Amman, Jordan

\section{Objectives}

1. To study the pattern of pathogens causing UTI in children in Jordan

2. To study the frequency of E. coli resistance to antibiotics.

Settings and method A prospective study of all cases of UTI presented to our pediatric department both in-patient and out-patient over two years (2010 and 2011). Studying the age and sex, the causative pathogens and their sensitivity and resistance to antibiotics. RESULTS: Age: Under 1 year of age 26 cases (21\%), 1-5 years :51 cases(42\%). Above 5 years: 37 cases (32\%).

Sex Females 94 cases (82\%), Males 20 cases (18\%). The ratio of 4.7:1.

The total number of cases was 114 including: 79 cases of $\mathrm{E}$. Coli(64\%), 29 cases of Klebsiella sp.(23\%),7 cases of Enterobacter sp. $(6 \%), 5$ cases of Proteus sp.(4\%), 2 cases of Staphylococcus aureus $(2 \%)$ and 1 case of Pseudomonas sp. (1\%).

The following antibiotics were administered according to the sensitivity of E. Coli and other factors:

Amikacin in 29 cases (36\%), Cefixim 27 cases (34\%), Amoxy-clav 13 cases $(17 \%)$.

Cephtriaxone 4 cases (5\%),Cefpodoxime 3 cases(4\%), Cefuroxime 3 cases. (4\%).

Conclusion UTIs are more common in girls and in toddlers.

E. coli is the commonest organism causing UTI followed by Klebsiella sp.

* Parenteral Amikacin was the drug of choice in about one third of cases of UTIs caused by E. coli which were resistant to the previously used antibiotics.

*Cefixim is the best oral antibiotic followed by Amoxy-clav. 